\title{
Slide Device
}

National Cancer Institute

\section{Source}

National Cancer Institute. Slide Device. NCI Thesaurus. Code C50178.

A flat rectangular piece of glass on which specimens can be mounted for microscopic study. 